\title{
VARIEDADE DE BATATINHA "EIGENHEIMER" (SOLANUM TUBEROSUM L.)
}

\author{
O. J. Boock
}

Engenheiro agrônomo, Seç̧ào de Raizes e Tubérculos, Instituto Agronômico de Campinas

\section{1 - INTRODUÇÃO}

A finalidade do presente trabalho é relatar o comportamento da variedade Eigenheimer, no que diz respeito à adaptação, resistência às moléstias e pragas, precocidade, produção, etc, sob as condições de solo, clima e épocas de cultivo no Estado de São Paulo. Êsse relato foi feito, em quase a sua totalidade, baseado em observações e trabalhos experimentais (cêrca de uma centena de experiências instaladas), levados a efeito pelo Instituto Agronômico de Campinas ( ${ }^{1}$ ).

A Eigenheimer foi obtida na Holanda, por G. Veenhuizen, no ano de 1890 e lançada no mercado em 1893. $\hat{E}$ proveniente do cruzamento das variedades Blauwe Reuzen e Fransen (1). Segundo Snell (14), as variedades que lhe deram origem, pelo cruzamento, foram Blaue Riezen (como planta feminina) e Fransche (como fornecedora de pólen). Essa variedade também é conhecida por Nektar der Saatzuchtwirtschaft Graf. v. Bassewitz, Rittergut Kläden, Kreiss Stendal (14), Grüger e Börger.

Os primeiros tubérculos dessa variedade foram recebidos no Instituto Agronômico em fevereiro de 1930. Com êles foram iniciados estudos de seu comportamento sob várias condições do Estado (10). A partir dessa época foram introduzidas outras partidas, fornecidas por revendedores, pelo govêrno holandês, ou por firmas produtoras nesse país e na Inglaterra. Por parte dos agricultores, a aceitação dessa variedade foi boa, passando então a serem feitas grandes importações.

Para maiores esclarecimentos, são dadas, no quadro 1, as quantidades de caixas de batata Eigenheimer entradas no Estado de São Paulo, durante os anos de 1935 a 1940, período em que o serviço de distribuição de material estêve a cargo da Seç̧ão de Raízes e Tubérculos, do Instituto Agronômico. Nesse mesmo quadro, pode-se verificar ainda quais os municípios que a receberam em maior quantidade.

(1) $\mathrm{Na}$ execuçăo de cliversos experimentos aqui relatados, com esta variedade, vários técnicos tomaram parte ativa, dentre êle os engenheiros af̧ônomos C. A. Krug, Jorge Biprrenbach de Castro, Jorge Kiehl (falecido) e Juiz A. Niscri. 
Quadro 1.-Distribuição, por município do Estado de São Paulo, de batatas-semente da variedade Eigenheimer, importadas no periodo de 1935 a 1940 . Número de caixas de 30 quilos

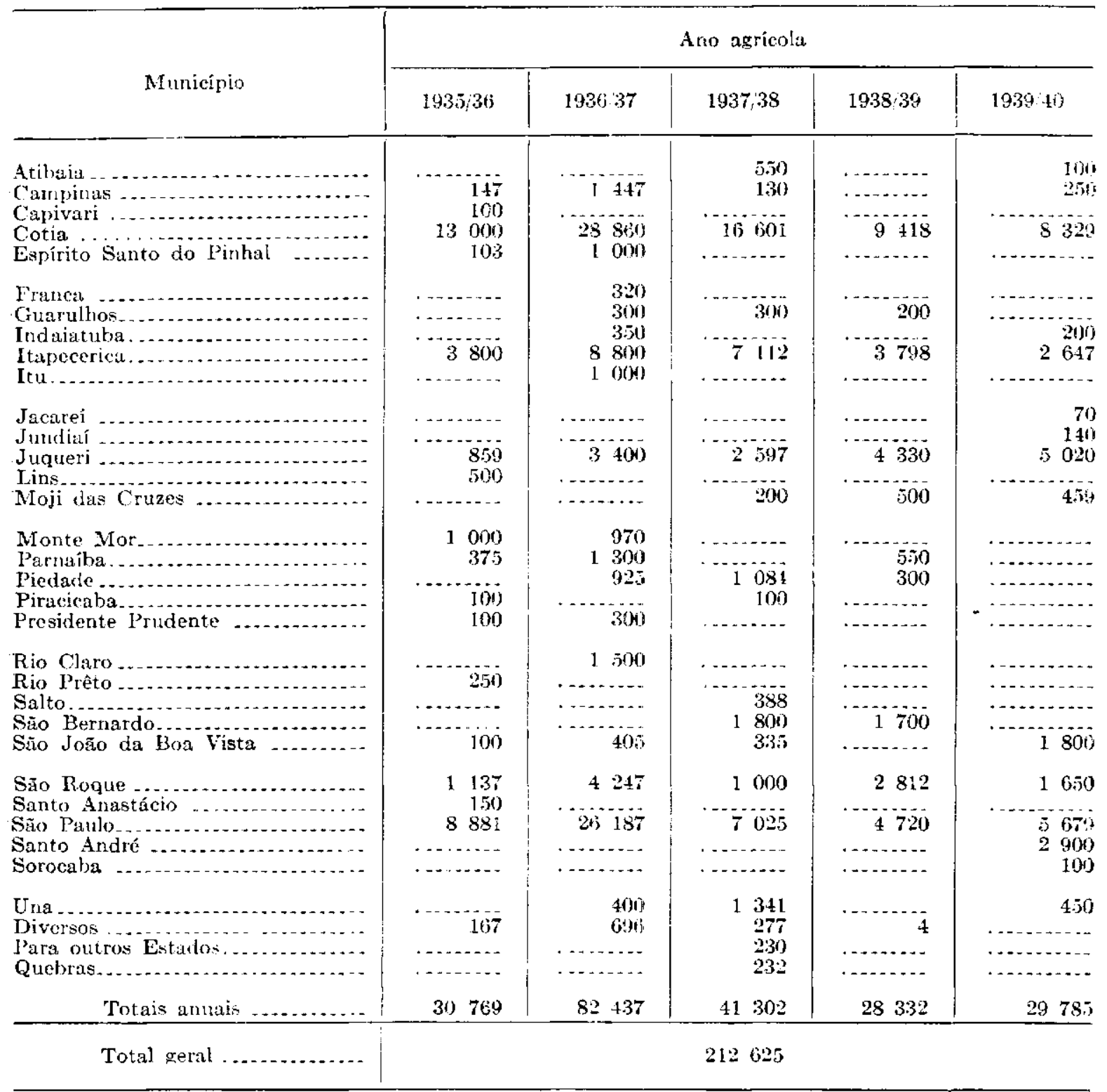

Verifica-se, pelo quadro 1, que os municípios de Cotia, Itapecerica, Juqueri, São Roque e São Paulo (Capital) foram os que mais importaram a variedade Eigenheimer. Durante os anos de 1935 a 1940 , as importacoos feitas através do pôrto de Santos alcançaram um total de 212.625 caixas de 30 quilos, o que vem corresponder, por ano, às seguintes percentagens sobre o total importado do estrangeiro (5): 
Por essa relaŗão se pode deduzir que a Eigenheimer foi a variedade mais importada, pois, no ano de $1937 / 38$, apesar de ter havido decréscimo na sua importação em relação às demais variedades, ainda assim foi supcrior a 50 por cento $(53,71 \%)$. Além de São Paulo, outros estados brasileiros importaram-na, porém em menor escala.

A variedade Eigenheimer é muito cultivada na Holanda, visando principalmente a exportação para a Alemanha, onde é utilizada não só para consumo humano como também na indústria e para forragem (13). Nas regiões de terras argilosas do oeste da Holanda, ela ocupa 25 por cento da área cultivada com batata, e 15 por cento da área cultivada nas regiões de terras arenosas $(\mathbf{1})$.

\section{2 - DFSCRIÇÃO E CARATERISTICOS PRINCIPAIS}

Com referência aos seus caraterísticos, são os seguintes os de maior interêsse :

Tubérculos : oval-alongados, irregulares (fig. 1), pouco cheios, gemas profundas, película amarelada, brotos de côr violeta na presença da luz ;

Polpa : amarela, de bom teor em fécula ;

Maturação : meio precoce; sob condições normais de cultivo leva eèrca de 90 a 115 dias para completar o período do vegetação;

Vegetação : abundante, as fôlhas são verde-escuras sem brilho, os folíolos estreitos e ponteagudos, as hastes finas, altas e $\mathrm{em}$ grande número, de côr verde, salpicado de matrom-azulado, principalmente na base ;

Florescimento : abundante, flores de côr branca;

Frutifieação : dificilmente produz frutos;

Produtividade : é considerada no Estado de São Paulo como uma variedade de rendimento elevado, produzindo tubérculos de tamanho médio e com grande percentagem de tubérculos miúdos.

Adaptação : tem-se adaptado a quase todos os tipos de solos do Estado de São Paulo. Por ser muito sujeita ao chamado "embonecamento" (1), não é cultivada em terrenos muito arenosos, como nos da Alta Sorocabana;

Qualidade : devido à rapidez da sua brotação, é uma varicdade que pode ser cultivada duas vêzes por ano, o que não se dá com algumas variedades, como a Voran, Alpha, etc. Êste cara terístico é de importância para as nossas condições culturais. É um pouco suscetível às "manchas internats" $\left({ }^{2}\right)$, e suscetível à Phytophthora infestans (Mont) de Bary, que afeta a folhagem e o tubérculo, e à Alternaria solani (Ell. e Martin) Jones e Grout.

\section{3-QUALIDADE CULINARIA E VALOR NUTRITIVO}

A Eigenheimer é utilizada em diversos países, tanto para indústria e forragem como para mesa. Entre nós, por têrmos outras fontes de forragem

(1) Formaç̃o de tubérculos secundários.

(2) Manchas ferruginosas de origem nāo determinadu. 


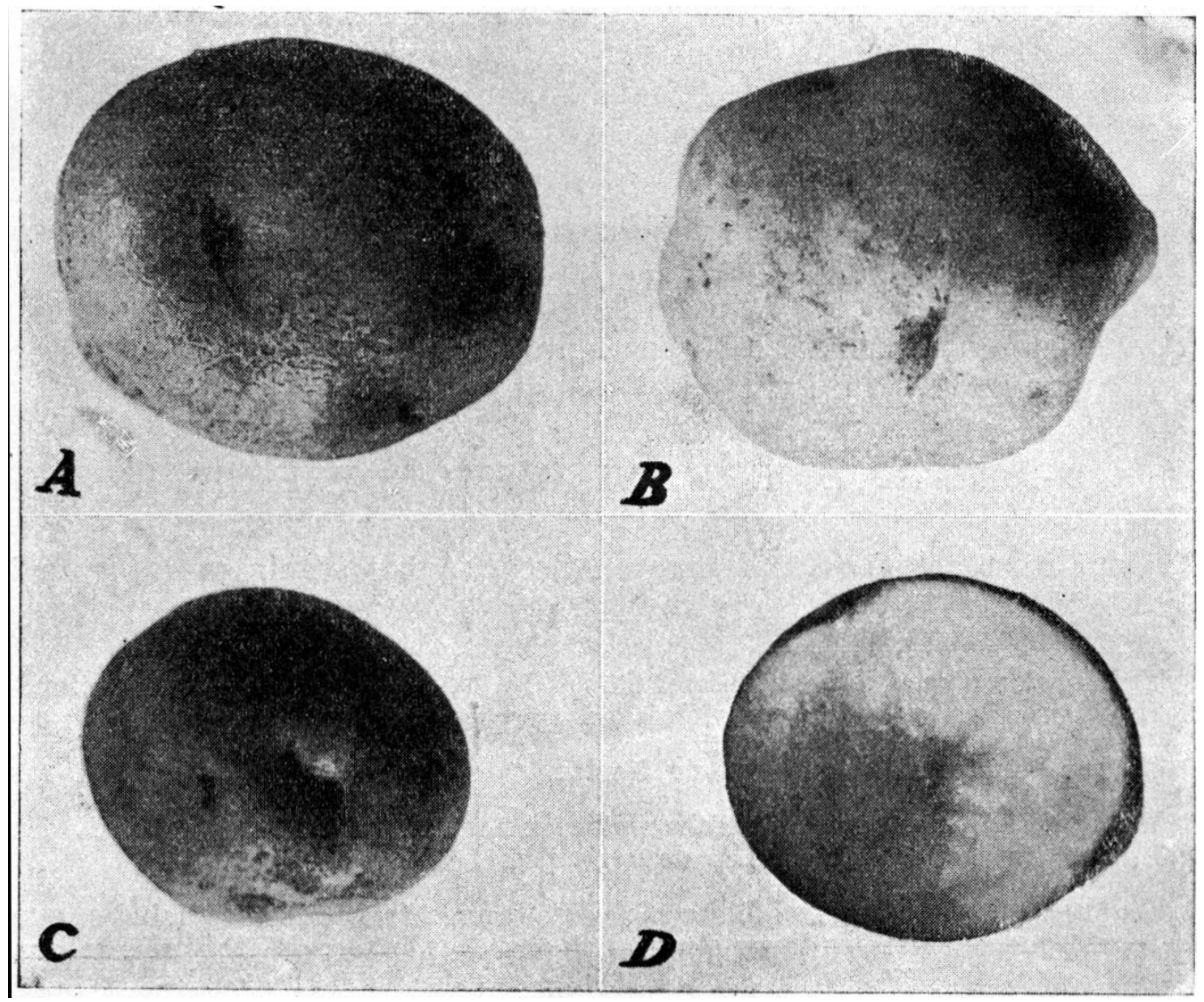

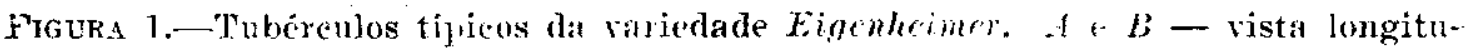
dinal ; $C$-vista apical; $D$ - corte transversil.

- de léeula mais baratas, como, por exemplo, a manoioca, a araruta, a batata doce, etc., ela sòmente é utilizada como alimento humano. Fmbora apreciada pelo consumidor paulista, temos em cultura, no Estado, diversas ontras variedades de excelente textura e paladar, como, por exemplo, a Eersteling e a Bintje, também holandesas, e que são melhor "otadas.

Os seus tubérculos são firmes e de bom teor em fécula, e, ao serem submetidos ao cozimento, não se desfazem, o que permite a confeç̧ão de saladas, batatas cozidas, etc. Por apresentarem ats gemas profundas e serem stijcitos ao embonecamento, sofrem, no ato do descascamento, um maior desperdício do que os de variedades de gemas rasass e que não "embonecam", "omo, por exemplo, a Eersteling. Hla é mais apreciada para consumo logo após a colheita, pois, armazenada longo tempo, tende a escurecer quando cozida. Na Holanda é tida como uma rariedade de ótimo valor culinário, bom teor em fécula e protéñ , boa conservação e teor médio em vitamina C (1). Remy (13), na Alemanha, at considera romo de rendimento médio f:m férnla. 


\section{4 - RESISTENCIA ÀS MOLÉSTIAS E PRAGAS}

A Eigenheimer não apresenta resistência às moléstias da folhagem, causadas pelo chamado "crestamento tardio", também conhecido por "requeima", "pressa" ou "míldio", e cujo agente causal é o fungo Phytophthora infestans. Esse fungo tem causado grandes danos às culturas, não só desta como de muitas outras variedades ( 2 e 3 ), exigindo aspersões constantes com a finalidade de evitar a sua manifestação.

No Rio Grande do Sul, dentre diversas variedades estudadas, tôdas se mostraram atacadas pela "murcha bacteriana" - Pseudomonas solanacearum E. F. Smith. - e, dentre elas, a Eigenheimer (9).

Na lista descritiva de variedades de batata organizada pelo govêrno holandês (1), a variedade em estudo é citada como um pouco difícil de se manter em bom estado de sanidade quanto às moléstias de vírus ; medianamente resistente ao "embonecamento" e muito sensível ao mosaico leve e grave.

Pelos resultados obtidos em três ensaios de variedades (8), verifica-se que a Eigenheimer acusou, em cada um dêles, respectivamente, 5,1, 0,0 e 2,1 por cento de plantas com "necrose do tôpo", existindo variedades, como a Rotweissragis, Bevelander e Estimata, que chegaram a apresentar cêrca de 18 por cento. A Eigenheimer mostrou-se sujeita ao chamado "coração prêto" e ao "embonecamento" (7). Pelas observações feitas durante vários anos por técnicos do Instituto Agronômico, chegou-se à conclusão de que essa variedade é muito suscetível à murcha bacteriana, causada por Pseudomonas solanacearum, à sarna comum, causada por Streptomyces scabies (Thaxter) Waksman et Henrici, às galhas, provocadas por nematóides - Meloidogyne sp., à Phytophihora infestans, à Alternaria solani à Rhizoctonia solani $K \ddot{u} h n$, fato êsse que pode ser visto, em parte, no quadro 2.

No quadro 2 podemos constatar ainda que a Eigenheimer se mostrou também suscetível aos alfinetamentos causados por Termitideos e à "sarna prateada", cujo agente causal é o Spondilocladium atrovirens Harz.

Esta variedade, à semelhança do que se observa com a Konsuragis, apresenta "manchas internas" (na polpa), também conhecidas por "manchas ferruginosas" ou "Chocolate". Essa anormalidade, embora seja constatada com menor intensidade do que a observada na Konsuragis (6), ocorre devido às condições climáticas e, principalmente, nas culturas feitas no período compreendido entre setembro-fevereiro. Essas manchas comunicam aos tubérculos um péssimo aspecto, tornando-os, além disso, ardidos após o cozimento.

Do ponto de vista da conformação dos tubérculos, temos constatado ser essa variedade muito sujeita aos "embonecamentos", "anormalidades" e "afilamentos", fato êsse que também pode ser verificado no quadro 2 . 
Quadro 2.-Ocorrência de moléstias, pragas a anormalidades, nos tubérculos da variedade Eigenheimer, colhidos em experiêveias instaladas em várias localidades do Estado de São Paulo. (Média das experiências, por localidade, de 1934 a 1950)

\begin{tabular}{|c|c|c|c|c|c|c|c|c|c|c|c|c|c|c|}
\hline \multirow{2}{*}{ IOCALIDADE } & \multirow{2}{*}{ 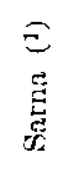 } & \multirow{2}{*}{ 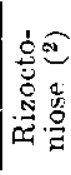 } & \multirow{2}{*}{ 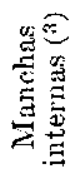 } & \multirow{2}{*}{ 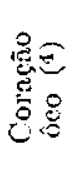 } & \multicolumn{2}{|c|}{ Podridão } & \multirow{2}{*}{ 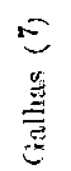 } & \multirow{2}{*}{ 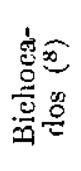 } & \multirow{2}{*}{ 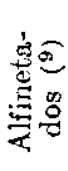 } & \multirow{2}{*}{ 总总 } & \multirow{2}{*}{ 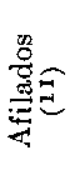 } & \multirow{2}{*}{ 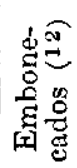 } & \multirow{2}{*}{ 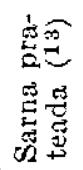 } & \multirow{2}{*}{ 总 } \\
\hline & & & & & $\begin{array}{c}\text { sêcal } \\
\left({ }^{5}\right)\end{array}$ & mole & & & & & & & & \\
\hline & $\%$ & $\%$ & $\%$ & $\%$ & $\%$ & $\%$ & $\%$ & $\%$ & $\%$ & $\%$ & $\%$ & $\%$ & $\%$ & $\%$ \\
\hline Canp & 1,4 & 0,8 & $2, \mathrm{c}$ & & 0,3 & & 36,4 & 8,0 & 0,8 & $1, \mathrm{C}$ & 7,8 & 3,2 & & \\
\hline & 3,8 & & 0,3 & 0,5 & 1,3 & 0,3 & 10,0 & 9,3 & 7,3 & 38,8 & 2,5 & 3,7 & 5,5 & \\
\hline Itaiquara & $\begin{array}{l}4,0 \\
6,0\end{array}$ & $\begin{array}{l}5,0 \\
2,5\end{array}$ & $\cdots$ & 1,5 & 1,3 & 0,5 & $\begin{array}{l}5,0 \\
2,8\end{array}$ & 7,0 & 29,8 & 1,3 & 5,0 & 7,0 & 3.0 & \\
\hline Itar & 17,0 & 2,0 & & & & & & $e, 0$ & 38,0 & & 5,0 & 19,0 & 12,0 & \\
\hline$\cdots$ & & 1,0 & 0,5 & 0,5 & 2,5 & & 12,8 & 6,3 & 13,0 & 3,8 & 5,3 & 1,5 & 1,0 & \\
\hline dente Prudente. & $\begin{array}{r}23,3 \\
4,0\end{array}$ & 4,7 & $\cdots$ & $-\cdots-$ & 1,3 & 0,7 & 50 & $\cdots$ & 32,7 & $\cdots$ & 4,7 & 13,3 & & $\cdots$ \\
\hline & & & & & & & & & & & & & & \\
\hline Sa & $\begin{array}{r}34,3 \\
5,0\end{array}$ & 1,3 & $\begin{array}{r}21,0 \\
1,3\end{array}$ & 1,0 & $\ldots$ & $\cdots$ & 14.7 & 1,8 & 1,3 & 10 & 14,5 & 8,0 & 1,3 & $\cdots$ \\
\hline & 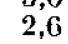 & c, & 4,0 & 1,0 & 15,3 & $\cdots$ & $\begin{array}{r}1.1 \\
0.8\end{array}$ & $\begin{array}{l}2,0 \\
5,4\end{array}$ & 10,8 & 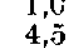 & $\begin{array}{l}4,0 \\
7,0\end{array}$ & $\begin{array}{r}2,3 \\
10,4\end{array}$ & $\ldots$ & \\
\hline & 14,8 & 2,0 & $x$ & . & 00 & -n. & & & & & & & 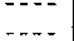 & \\
\hline Varg. Grande d & 13,0 & 7,0 & $\ldots$ & 6,0 & - & $\ldots$ & 2,0 & 5,0 & 37,0 & 3,0 & 6,0 & 1,0 & $\cdots$ & 1,0 \\
\hline
\end{tabular}

(1) Streptomyces scabies. (2) Rhizoctonia solani. (3) Manchas ferruginosas de origem não determinada. (4) Devido a condições de ambiente. (5) Podridões causadas principalmente por Fusarium. (6) Podridóes causadas principalmente por bactérias. ( $\left.{ }^{7}\right)$ Galhas provocadas por nematóides. (8) Batatas comidas por insetos. $\left({ }^{9}\right)$ Danos causados pelos chanados vermes arame, "Wire-worme", e cupins - Termilídeos, e que se assemelham a fuos feitos com alfinêtes. (10) Tubérculos defeituosos. (11) "Spindling tubers". (12) Formação de tubéreulos secundários. (13) Manchas causadas pelo Spondylocladium atro$v$ irens. (14) Racbaduras dos tubérculos, à semelhanga de fendas, como no "Yellow dwarf".

Dados coligidos pela Secção de Raízes e Tubérculos, do Instituto Agronômico, durante os anos de 1937 a 1940 , mostram o estado dessas sementes, quando chegaram ao nosso país (quadro 3).

Qtavro 3.- Ocorrência de moléstias, pragas e outras anormalidades, em tubérculos de batatas-semente de partidas da variedade Eigenheimer, recebidas da Holanda, de 1937 a $1942\left({ }^{1}\right)$. Resultados médios das partidas examinadas

\begin{tabular}{|c|c|c|c|c|c|c|c|c|c|c|c|c|c|c|c|c|c|}
\hline \multirow{2}{*}{ 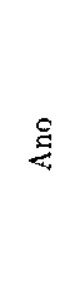 } & \multirow{2}{*}{ 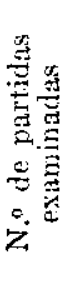 } & \multirow{2}{*}{ 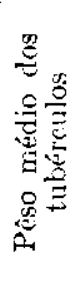 } & \multicolumn{2}{|c|}{ Sarna } & \multicolumn{2}{|c|}{$\begin{array}{c}\text { Rizoctc- } \\
\text { niose }\end{array}$} & \multirow{2}{*}{ 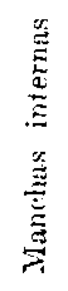 } & \multicolumn{2}{|c|}{ Podridão } & \multicolumn{2}{|c|}{$\begin{array}{l}\text { Tubér- } \\
\text { culos }\end{array}$} & \multirow{2}{*}{ 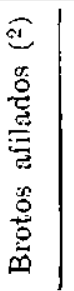 } & \multirow{2}{*}{ 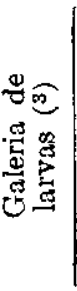 } & \multirow{2}{*}{ 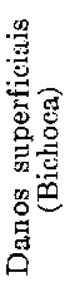 } & \multirow{2}{*}{ 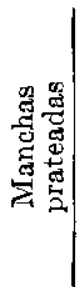 } & \multirow{2}{*}{ 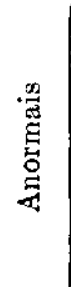 } & \multirow{2}{*}{ 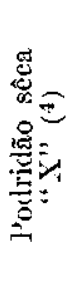 } \\
\hline & & & 兽 & 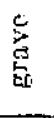 & 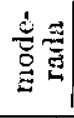 & 㒬 & & 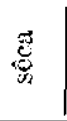 & $\stackrel{c}{0}$ & 紊尊 & 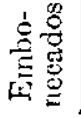 & & & & & & \\
\hline & & $g$ & $\%$ & $\%$ & $\%$ & $\%$ & $\%$ & $\%$ & $\%$ & $\%$ & $\%$ & $\%$ & $\%$ & $\%$ & $\%$ & $\%$ & $\%$ \\
\hline 937 & 24 & 43 & $11, \tilde{5}$ & 0,5 & 9,7 & 1,4 & 0.3 & 5,3 & -... & 0,3 & 0,9 & 0,1 & 0,6 & 0,4 & 0,7 & -- & \\
\hline 938 & 16 & 47 & 13,9 & 0,2 & 8,7 & 0,9 & 0,2 & 5,1 & 0,1 & ... & 0,9 & 0,1 & 0,1 & 2,1 & 3,6 & & \\
\hline 939 & 17 & 37 & 24,5 & 1,9 & 13,5 & 1.7 & & 0,5 & 0.2 & 0,2 & 1,7 & 1,1 & & 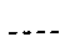 & 11,5 & 5,2 & 5,0 \\
\hline 40 & 20 & 42 & 14,1 & 0,5 & 18,1 & 1,3 & $\ldots$ & 0,5 & & 1,9 & 0,8 & 0,4 & 0,1 & $\ldots$ & 15,8 & 3,0 & 6,9 \\
\hline & & 42,2 & 16.0 & 0,8 & 12,5 & 1,3 & 0.1 & 2,8 & 0,07 & 1,1 & 1,1 & 0,4 & 0,4 & 0,6 & 7,9 & $4,1^{*}$ & $\tilde{5}, 9^{*}$ \\
\hline
\end{tabular}

(1) Exames feitos pelo Sr. Ludovico Bonatto, funcionário da Seccão de Raízes e Tubérculos, do Instituto Agronómico de Campinas.

(2) "Spindle sprouts".

(3) Perfuracōes causadas por larvas.

(4) Fusarium sp.

Média de 1939 e 1940. 
Observando o quadro 3, que resume êsses dados, pode-se concluir : $a$ ) o pêso médio era de 42,2 gramas, portanto ótimo para as nossas condições culturais ; b) apresentavam médias de $16 \%$ de sarna moderada, $0,8 \%$ de sarna grave, $12,5 \%$ de rizoctoniose moderada, $1,3 \%$ de rizoctoniose grave, $0,1 \%$ de manchas internas, $2,8 \%$ de podridão sêca, $0,07 \%$ de podridão mole, $1,1 \%$ de tubérculos afilados e embonecados, $0,4 \%$ de brotos afilados e galeria de larvas, $0,6 \%$ de danos superficiais (bichoca), $7,9 \%$ de mancha prateada, $4,1 \%$ de anormais, e 5,9\% de podridão sêca " $X$ ". Não constatamos nenhum caso de coração ôco (em parte pelo fato de os tubérculos não serem graúdos), galhas provocadas por nematóides e murcha bacteriana. Quanto a êste

QUADro 4.-Percentagens médias de plantas da variedade Eigenheimer, com sintomas de moléstias de vírus, e fracas, observadas em experiências instaladas em várias localidades do Estado de São Paulo (1)

\begin{tabular}{|c|c|c|c|c|c|c|}
\hline Localidade & $\begin{array}{l}\text { "Mild } \\
\text { mosaic }\end{array}$ & $\begin{array}{c}\text { Crin- } \\
\text { kle }\end{array}$ & $\begin{array}{l}\text { "Rugose } \\
\text { mosaic }\end{array}$ & $\begin{array}{l}\text { " Leaf- } \\
\text { roll " }\end{array}$ & $\begin{array}{l}\text { Necrose } \\
\text { do tôpo }\end{array}$ & $\begin{array}{c}\text { Plantas } \\
\text { fracas }\end{array}$ \\
\hline 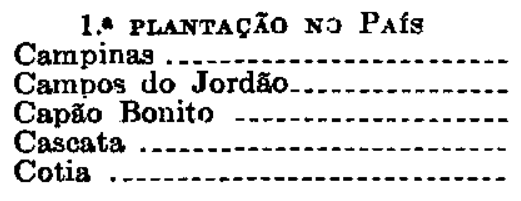 & $\begin{array}{l}\% \\
0,1 \\
3,8 \\
0,0 \\
3,1 \\
2,6\end{array}$ & $\begin{array}{l}\% \\
0,1 \\
0,0 \\
0,0 \\
0,1 \\
0,3\end{array}$ & $\begin{array}{l}\% \\
0,0 \\
0,0 \\
0,0 \\
0,0 \\
0,0\end{array}$ & $\begin{array}{l}\% \\
0,1 \\
0,0 \\
0,1 \\
0,0 \\
0,4\end{array}$ & $\begin{array}{l}\% \\
1,2 \\
0,0 \\
0,0 \\
0,0 \\
0,0\end{array}$ & $\begin{array}{l}\text { \% } \\
0,9 \\
0,0 \\
1,9 \\
\mathbf{0 , 1} \\
\mathbf{4 , 2}\end{array}$ \\
\hline 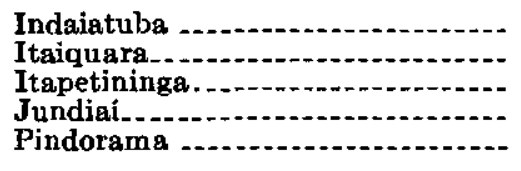 & $\begin{array}{r}0,3 \\
2,7 \\
0,0 \\
1,5 \\
21,4\end{array}$ & $\begin{array}{l}0,0 \\
0,0 \\
0,0 \\
0,0 \\
0,0\end{array}$ & $\begin{array}{l}0,0 \\
0,7 \\
0,0 \\
0,5 \\
0,0\end{array}$ & $\begin{array}{l}0,0 \\
0,0 \\
0,5 \\
0,5 \\
0,0\end{array}$ & $\begin{array}{l}0,0 \\
0.0 \\
0,0 \\
1,5 \\
0,0\end{array}$ & $\begin{array}{r}0,0 \\
1,2 \\
11,5 \\
1,0 \\
0,0\end{array}$ \\
\hline $\begin{array}{l}\text { São Bento do Sapucaí... } \\
\text { São Roque } \\
\text { Sorocaba } \\
\text { Taipas } \\
\text { Tietê } \\
\text { Tupi... Grande do Sul } \\
\text { Vargem Grand }\end{array}$ & $\begin{array}{l}0,0 \\
1,0 \\
0,2 \\
2,0 \\
1,3 \\
1,8 \\
0,2\end{array}$ & $\begin{array}{l}0,0 \\
1,2 \\
0,3 \\
0,0 \\
0,9 \\
0,0 \\
0,0\end{array}$ & $\begin{array}{l}0,0 \\
0,0 \\
0,0 \\
0,0 \\
0,0 \\
0,0 \\
0,0\end{array}$ & $\begin{array}{l}0,5 \\
0,0 \\
0,0 \\
0,0 \\
1,1 \\
0,0 \\
0,0\end{array}$ & $\begin{array}{l}0,0 \\
0,0 \\
0,0 \\
0,0 \\
3,4 \\
2,0 \\
0,0\end{array}$ & $\begin{array}{l}0,2 \\
1,7 \\
0,8 \\
0,0 \\
0,2 \\
0,0 \\
2,7\end{array}$ \\
\hline Média_-_.-.-... & 2,5 & 0,2 & 0,1 & 0,2 & 0.5 & 1,6 \\
\hline $\begin{array}{l}\text { 2.a PLANTAGR̃o No PAís } \\
\text { Campinassonito } \\
\text { Capão Bonito } \\
\text { Caseata } \\
\text { Jundiaí } \\
\text { Indaiatuba } \\
\text { Itapetininga }\end{array}$ & $\begin{array}{r}1,4 \\
0,0 \\
29,0 \\
0,0 \\
8,0 \\
0,0\end{array}$ & $\begin{array}{l}0,0 \\
0,0 \\
0,0 \\
0,0 \\
1,0 \\
0,0\end{array}$ & $\begin{array}{l}0,5 \\
0,0 \\
0,0 \\
0.0 \\
1,0 \\
0,0\end{array}$ & $\begin{array}{l}1,5 \\
1,0 \\
0,0 \\
0,2 \\
0,0 \\
0,0\end{array}$ & $\begin{array}{l}0,4 \\
0,0 \\
0,0 \\
0,0 \\
0,0 \\
0,0\end{array}$ & $\begin{array}{l}1,3 \\
0,0 \\
0,0 \\
0,2 \\
0,0 \\
2,0\end{array}$ \\
\hline 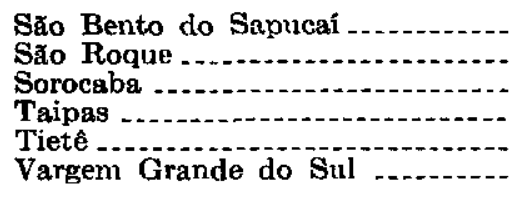 & $\begin{array}{l}0,0 \\
1,7 \\
0,0 \\
2,0 \\
0,0 \\
0,0\end{array}$ & $\begin{array}{l}0,2 \\
0,0 \\
0,0 \\
0,0 \\
0,2 \\
0,0\end{array}$ & $\begin{array}{l}0,0 \\
0,2 \\
0,1 \\
0,0 \\
0,0 \\
0,0\end{array}$ & $\begin{array}{l}0,0 \\
0,2 \\
0,0 \\
0,0 \\
0,0 \\
0,0\end{array}$ & $\begin{array}{l}0,0 \\
0,0 \\
0,0 \\
0,0 \\
0,0 \\
0,0\end{array}$ & $\begin{array}{l}0,0 \\
0,2 \\
1,9 \\
0,0 \\
0,0 \\
0,0\end{array}$ \\
\hline Média_...................... & 3,5 & 0,1 & 0,2 & 0,2 & 0,03 & 0,5 \\
\hline 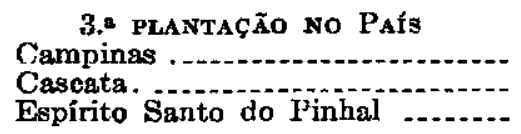 & $\begin{array}{l}21,9 \\
23,7 \\
67,9\end{array}$ & $\begin{array}{l}0,0 \\
0,5 \\
0,0\end{array}$ & $\begin{array}{l}3,7 \\
0,7 \\
0,0\end{array}$ & $\begin{array}{l}0,1 \\
0,0 \\
0,0\end{array}$ & $\begin{array}{l}0,0 \\
0,0 \\
0,0\end{array}$ & $\begin{array}{l}1,5 \\
0,9 \\
0,0\end{array}$ \\
\hline Média & 37,8 & 0,2 & 1,5 & 0,03 & 0,0 & 0,8 \\
\hline
\end{tabular}

(1) Média de 47 experiências. 
último item, podemos informar que, em nossas observacões, ficon provado ser a referida rariedade, à semelhança das demais cultivadas no Wstado, suscetível à murchadeira -- Pseudomonas solanacearum.

Das partidas importadas, a maioria pertencia à classe "C", apresentando os tubéreulos, de modo geral, hom ispecto e quase todos bem brotados.

Quanto às moléstias causadas por vírus, diversas observaços foram feitas em nossas experiências, conforme resumimos no quadro 4.

O exame dêsse quadro nos indica que a rariedade se tem mostrado muito sujeita ao "mild mosaic", pois houve casos, como, por exemplo, em Pindorama (1. plantação), Cascata (2." e 3." plantação), Campinas e Espírito Santo do Pinhal (3." plantação), onde as percentagens foram superiores a $20 \%$ (respectivamente $21,4-29,0-23, \bar{i}, 21,9$ e $67,9 \%$ ). Quanto aos demais tipos de rírus, as percentagens foram, de modo geral, baixas, a não ser a de 3.7\% de "rugose mosaic" em Campinas, na terceira plantação. Quanto à necrose do tôpo, a percentagem mais elevada foi, em Tietê, de $3,4 \%$ (1. plantação).

Qradpo 5.- Médias dos periados de vegetação(1) e clas produções de tubéreulos obtidas para a variedade Figenheimer em 86 experiencias lte variedades de batatinha, instaladas

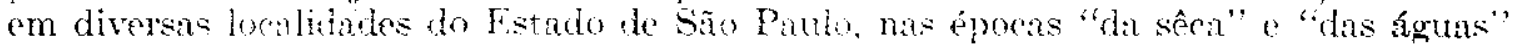

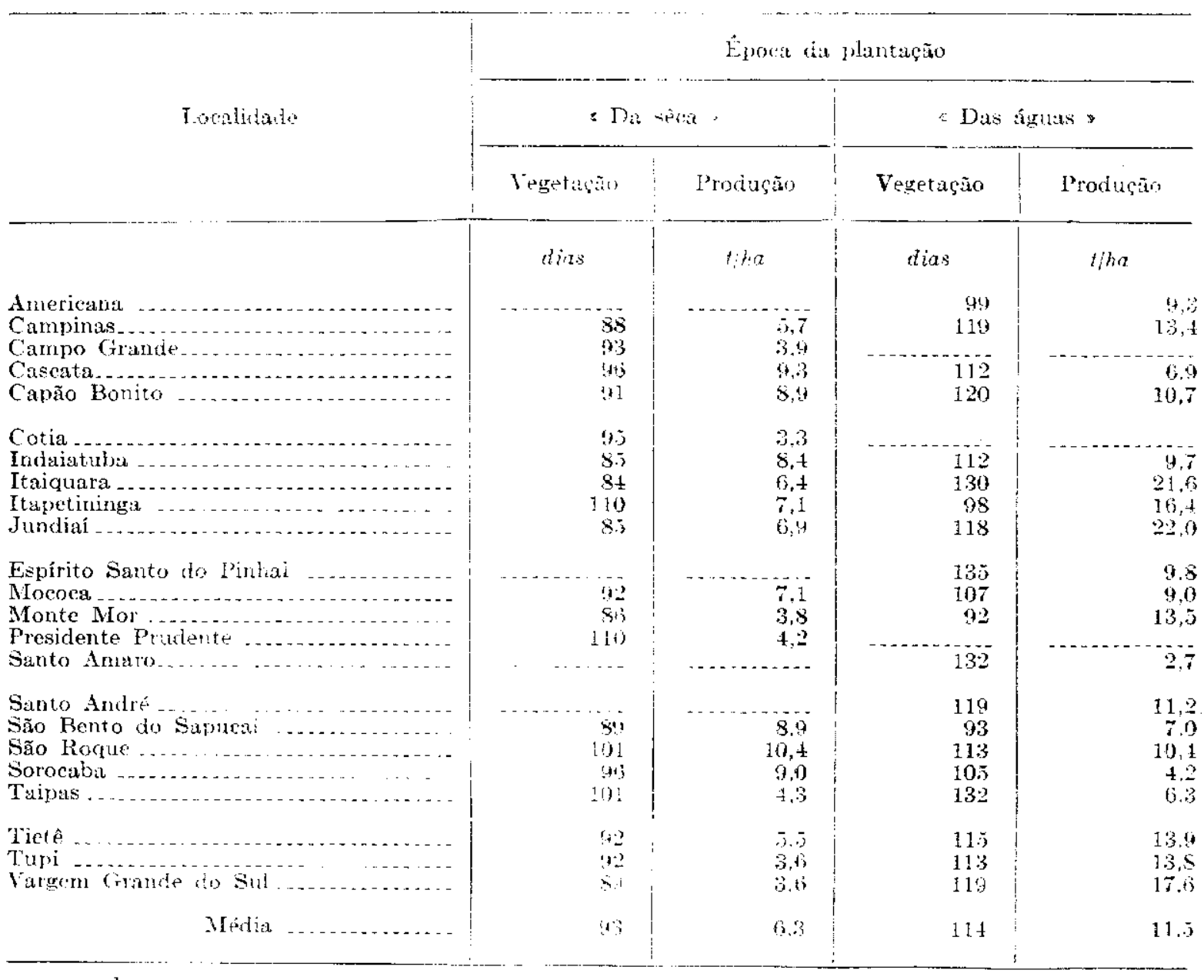




\section{j-PRODLTIVIDADE}

A Eigenheimer é cultirada em diversas zonas produtoras de batatinha do Estado de São Paulo e mesmo de outros estados, como Minas Gerais, Rio Grande do Sul e Paraná. A razão disso reside, principalmente, no fato de ter apresentado boas produções em quase todos os tipos de solos.

Baseando-nos em informasões do estrangeiro e nos resultados obtidos em nossos campos de aumento e, principalmente, nas experiências de variedades levadas a efeito pelo Instituto Agronômico de Campinas, em diferentes localidades do Estado de São Pazlo, podemos concluir que a variedade se tem portado relativamente bem (ressalvando os defeitos por embonecamentos). quando cultivada sob os mais diferentes tipos de solos, como, por exemplo, os salmouroes de Sorocaba, arenosos de Indaiatuba, argilosilicosos de Itaiquara, turfosos do Vale do Paraíba, etc., o que a tornou uma variedade cosmopolita, tal como a Konsuragis (6).

No quadro 5. damos as produços médias obtidas pela Eigenheimer em experiências leradas a efeito em diversas localidades, tanto para o período "da sêca", como o "das águas" (1).

Pelas médias de produções e dos meses correspondentes ao ciclo do plantio à colheita, podemos concluir que, na chamada plantação "das águas", de setembro a fevereiro, as produçôes são bem mais elevadas, e o ciclo vegetativo das plantas é maior do que no "da sêca".

Embora as produçōes sejam baixas no chamado período "da sêca", há necessidade imprescindível de ser feito êsse plantio entre nós, porquanto é com o produto dessa colheita que se efetua novo plantio no período seguinte, ou seja, no "das águas". É ainda por esta última razão que a variedade em aprȩ̣̂o tem tido boa aceitação, pois, sendo de brotação relativamente rápida e de ciclo vegetativo meio precoce, permite dois plantios num mesmo ano, condição essencial para o cultivo no Estado de São Paulo. Tal fato já não se dá com variedades tardias, como, por exemplo, a Voran, que, ou se faz um só cultiro por ano, tendo então que armazená-las em câmaras: frigoríficas especiais. ou então dois cultivos, com prejuízos para a produção, dado o elevado número de falhas que geralmente ocorre.

Para comprovar êsse tato, pode-se citar os seguintes resultados obtidos em experiências leradas a efeito pelo Instituto Agronômico (2 e 3). Batatassemente das variedades Eigenheimer e Voran, recebidas em janeiro, foram plantadas em fevereiro, dando, em média, produçóes de $7,3 \mathrm{t} / \mathrm{ha}$ para a Eigenheimer e 6,9 para a Voran. Com o produto dessa colheita, foi feito o segundo plantio, ou seja, o de setembro, e se obtiveram 16,0 t/ha para a primeira e $6, \bar{j}$ para a segunda. Podemos esclarecer que isso se deu exclusiramente devido ao fato de a Voran não estar brotada (é de brotação e desenvolvimento lento), wo passo que a Eigenheimer se apresentava com ótima brotação.

As produções médias, apresentadas na relação anterior, se assemelham, pràticamente, às alcançadas pela Konsuragis (6), também muito cultivada no Estado.

(1) Tôdas as experièncias recuberam adubações com fertilizantes químicos em doses completas de N. P e K. Ver citaçós $n^{\circ}, 2^{2}, 3,4,11,12$ e 13. 


\section{6-TIPOS IOOS TLBERCULOS}

Das expcriências levadas a efeito pelo Instituto Agronômico de Campinas, e pelas observações em culturas particulares, pode-se concluir que a Eigenheimer tem propensão para produzir acentuada percentagem de tubérculos por planta, bem como batatas do tipo médio e miúdo, o que pode fàcilmente ser verificado, principalmente quando o plantio é feito no chamado "período da sêca" (2 e 3). A fím de melhor poder comprovar êsse fato (1), são apontadas, no quadro 6 , as médias de trinta e cinco experiên(ias, por onde se verifica que, enquanto no período chuvoso se obtiveram $15,9 \%$ com pêso acima de 80 gramas e $13,1 \%$ abaixo de 20 , já no período sêco as percentagens obtidas foram, respectivamente, de 4,1 e 31,8 .

Quavro 6.-Percentagens médias de tipos de tubéreulos apresentados pela variedade. Eigenheimer (média de 35 experiências)

\begin{tabular}{|c|c|c|c|c|c|}
\hline Períado & $\begin{array}{l}\text { Aciniti } \\
\left.\text { de } 8^{\prime}\right)^{\prime} g\end{array}$ & $\begin{array}{l}\text { De } 69 \\
\text { at } 89 \stackrel{r}{=}\end{array}$ & $\begin{array}{l}\text { De } 40 \\
\text { a } 6909\end{array}$ & $\begin{array}{l}\text { De } 20 \\
a 47 \mathrm{~g}\end{array}$ & $\begin{array}{l}\text { Ahaixo } \\
\text { de } 20 \mathrm{~g}\end{array}$ \\
\hline & $\%$ & $\%$ & $\%$ & $\%$ & $\%$ \\
\hline 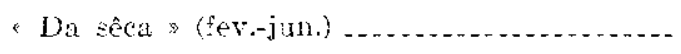 & 4,0 & 8.6 & 18.0 & 37,6 & 21,8 \\
\hline 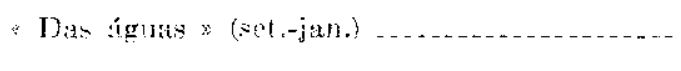 & 15.9 & 19,5 & 23,6 & 25,9 & 13,1 \\
\hline
\end{tabular}

\section{7 - COTAÇAO NO MERCADO}

De conformidade com os dados obtidos pela Cooperativa Agrícola de Cotia, e conhecidos através dos apontamentos diários das reuniós dos elassificadores e vendedores, a Eigenheimer acha-se inclúdat no grupo constituído pelas variedades Paraná Ouro, Konsuragis e Bevelander, também de polpa amarcla, o inferior às demais variedades, Bintje e Eersteling (3). Abaixo dela, enquadram-se as variedades de polpa branca.

\section{8 - DISCLSSÃO F RFSUMO}

A variedade de batatinha Eigenheimer toi obtida na Holanda por G. Veenhuizen e vem sendo cultivada há vários anos, em quase tôdas as zonas hatateiras do Fstado de São Paulo, por ser produtiva e por se adaptar a maioria dos tipos de solo e clima do mesmo Fstado. F meio precoce e brota ràpidamente, quando em armazenamento, permitindo, com isto, dois plantios por ano. Esta prática é das mais recomendadas para as nossas condições de cultivo. Os scus tubéreulos dificilmente produzem rachaduras (cracking) motivadas por condiçoes de ambiente.

Dentre as desvantagens que a variedade Figenheimer apresenta, podese citar a rápida degeneração, a facilidade de embonecamento, principalmente quando cultivada em terreno arenoso, fatos êtos que a tornam bastante diferente da Konsuragis. Além disso, a Eigenhoimer produz clevada perentagem de tubéreulos do tipo médio e miúdo e com gemas profundas.

(1) Adotanos a classificarão dos tubérculos de $20 \mathrm{em} 20$ mamas, an invés de tipce padrões, a fim

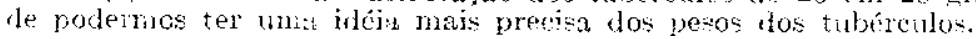


Em época chuvosa e quente, apresenta-se com manchas internas (chocolate), porém em percentagens menor do que a Konsuragis. A sua cotação no mercado se assemelha à das variedades Konsuragis, Paraná Ouro e Voran, sendo superior às das variedades de polpa branca e inferior à das variedades Bintje e Eersteling. $\hat{\mathbf{E}}$ suscetível à requeima, causada por Phytophthora infestans, à alternária, causada pela Alternaria solani, à murchadeira, causada por Pseudomonas solanacearum, à sarna comum, causada por Streptomyces scabies, e aos nematóides causadores de galhas, Meloidogyne sp.

Do exposto, podemos concluir que, pelas vantagens apresentadas, é a Eigenheimer uma das variedades recomendadas para o cultivo no Estado de São Paulo até que outra variedade possa substituí-la, como, por exemplo, a Konsuragis, que só não é cultivada no momento em tôdas as zonas batateiras do Estado por falta de batatas-semente.

\section{SUMMARY}

The behavior of the Irish potato variety "Eigenheimer" in the State of São Paulo has been studied. This variety grows well under the soil and climatic conditions present in potato areas of this state.

Eigenheimer is an early maturing variety and a good yielder. The tubers sprout readily in storage, permitting two plantings in a year to be made with same seed. It is susceptible to virus diseases, early and late blight, bacterial wilt, common seab, and root-knot nematode. It shows a tendency to develop second growth, and under rainy and hot weather is subject to internal brown spot.

The tubers of Eigenheimer are deep-eyed, and a large percentage of the crop consists of average and small-sized tubers. The marketing value of the Eigenheimer potato equals that of Konsuragis, Parana Ouro, and Voran, being higher than that of whitefleshed varieties, but lower than the value of Bintje and Eersteling.

\section{LITERATURA CITADA}

1. Anônimo. Variétés de pommes de terre - Vingt-cinquiéme liste descriptive des variétés de plantes de grande culture. Wageningen. Pays-Bas, pág. 11, $19 \tilde{5} 0$.

2. Boock, O. J. Variedades de batatinha (Solanum tuberosum L.) procedentes da Holanda, - Parte I. Resultados experimentais da primeira plantação no País, com tubérculos importados em 1947. Bragantia 8 : 25-52, fig. 1, est. 1-2, 1948.

3. Boock, O. J. Variedades de batatinha (Solanum tuberosum L.) procedentes da Holanda. - Parte II. Resultados experimentais da segunda plantação no Páśs, com tubérculos importados em 1947. Bragantia 8 : 53-73, fig. 1, est. 1, 1948.

4. Boock, O. J. Em Relatórios da Seção de Raízes c Tubérculos do Instituto Agronômico de Campinas, 1947 a 1949 (não publicados).

5. Castro, J. B., J. Kiehl, O. J. Boock e A. Pais de Camargo. Em Relatórios da Seç̧ão de Rázes e Tubérculos do Instituto Agronômico de Campinas. 1939 e 1940 (não publicados).

6. Castro, J. B., e O. J. Boock. Variedade de batatinha "Konsuragis". Bragantia $7: 151-177$, gráf. 1, est. 1-7. 1947.

7. Costa, A. S. e H. P. Krug. Moléstias da batatinha em São Paulo. Bol. do Instituto Agronômico de Campinas 14: 1-55, fig. 1-51. 1937. 
8. Costa, A. S. e J. Kiehl. Uma moléstia de batatinha. Necrose do tôpo causada por" vírus de "vira-cabeça". Jour. de Agronomia (Piracicaba) 1 : 193-202. 1938.

9. Costa Neto, J. P. da. A murcha bacteriana da batata. Circ. Secret Agric. Ind. c Com. Fst. R. G. do Sul (Pôrto Alegre) $47: 1-4.1941$.

10. Krus, C. A. Em Relatório da Secção de Genética do Instituto Agronômico de Campinas, $1929 / 30$ : pág. 212-245. 1935.

11. Krug, C. A., J. B. de Castro, A. S. Costa e A. P. Viegas. Em Relatórios da Seccio de Genética do Instituto Agronomieo de Campinas. 1931 a 1934. (não publicados).

12. Krug, C. A., J. B. de Castro, A. S. Costa t L. A. Nucci. Em Relatório do Instituto Agronômico de Campinas (Seçño de Genética). 1935: 36-72. 1936.

13. Remy, Th. Em Handbuch des Kartoffelbaues, pág. 312, Verlagsbuchandlung Paul Parey, Berlin. 1928.

11. Snell, K. Em Kartoffelsorten - Arbeiten des Fonchungsinstitutes fur Kartoffelbau an der Biologischen Reichsanstalt fie Land und Fortwirtsehaft Heft 5, 99, Ferlagshuchbandlung Paul Parey, Berlin. 1929. 